\title{
A neo-rectal bladder by uretero-rectal anastomosis: a case report
}

\author{
Xin Hai, Jingyan Yang \\ Department of Urology, Union Hospital, Tongji Medical College, Huazhong University of Science and Technology, Wuhan, China \\ Correspondence to: Jingyan Yang. Department of Urology, Union Hospital, Tongji Medical College, Huazhong University of Science and Technology, \\ Wuhan 430022, China. Email: xhyjy100@163.com.
}

\begin{abstract}
Urinary diversion has always been a great challenge for urologists. There are many reasons and various methods for urinary diversion in clinical practice. In this report, who was diagnosed with a pelvic fracture complicated by enterostomy, urethral stricture, and bilateral inferior ureteral stricture. We performed laparoscopic bilateral ureterorectal reimplantation for this patient. Postoperatively, the patient recovered well and was able to perform volitional emptying. Bilateral DJ stents were removed under ureteroscopy at 6 weeks postoperatively. Six months after operation, no hydronephrosis was found in both kidneys. No increase of blood urea nitrogen (BUN) and creatinine were observed in renal function examination. It is clearly stated that in the present report a modified version of Heitz-Boyer-Houvelac uretero-rectostomy technique was carried out, as the technically demanding surgical step of retrorectal pullthrough of the sigmoid colon was unneccesary given that the patient already had enterostomy. This surgery was performed laparoscopically and that the most relevant benefit for the patient was to avoid incontinent urinary diversion or possibly a more complex surgical procedure.
\end{abstract}

Keywords: Urinary diversion; uretero-rectal anastomosis; volitional emptying; ureteral stricture; urethral stricture; case report

Submitted Apr 09, 2021. Accepted for publication Jun 18, 2021.

doi: $10.21037 /$ tau-21-298

View this article at: https://dx.doi.org/10.21037/tau-21-298

\section{Introduction}

Urinary diversion is a great challenge in urological surgery, and it is also one of the hot spots in urology. Heitz-BoyerHouvelac uretero-rectostomy was introduced in 1912. Shaw reported that he performed ureterorectal anastomosis in male and female corpses and demonstrated the feasibility of this procedure in 1937 (1). After that, several articles reported the clinical application of this surgical method (2-4). A rectal bladder is established by implanting the ureters into the isolated rectum, utilizing a mucosa-to-mucosa anastomosis and an intramural tunnel (5). The sigmoid colon is brought to the surface in the perineum beneath the internal and external rectal sphincters by creating a tunnel posterior to the rectum in the hollow of the sacrum which maintains the normal anatomic position of the 2 systems (5). Ureterorectal anastomosis was generally used in patients with radical cystectomy or bladder exstrophy. Due to the controversy of postoperative complications, it has not been widely promoted so far. However, for some complex patients, the authors believe that this surgical approach may be more suitable. We present the following article in accordance with the CARE reporting checklist (available at https://dx.doi.org/10.21037/tau-21-298).

\section{Case presentation}

All procedures performed in studies involving human participants were in accordance with the ethical standards of the institutional and/or national research committee(s) and with the Helsinki Declaration (as revised in 2013). Written informed consent was obtained from the patient. A 52-year-old man was referred to our Urology Department with a diagnosis of bilateral ureteric strictures and urethral strictures. Approximately 27 years prior to his hospitalization, the man had a car accident in which he suffered fracture of the pelvic and had a complete ruptured posterior urethra and intestinal damage. Enterostomy and 


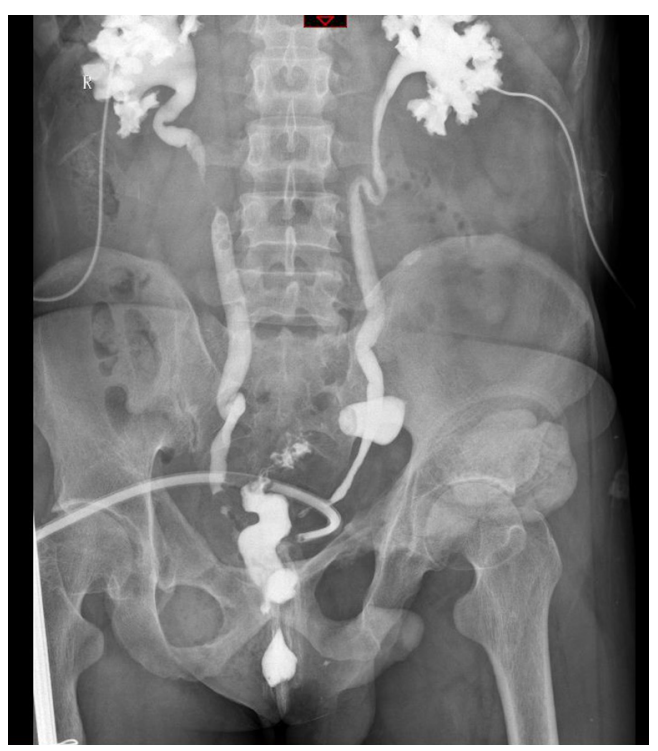

Figure 1 Image of bilateral ureterographic (contrast agent being in the ureter).

cystostomy were performed. The enterostomy is at the sigmoid level. The patient had an unsuccessful urethroplasty repair 25 years ago. One year ago, he was hospitalized due to high fever $\left(39^{\circ} \mathrm{C}\right)$, and the examination revealed bilateral distal ureteral strictures with hydronephrosis. So he was performed a bilateral nephrostomy. Routine urine examination in our hospital indicated urinary tract infection, and urine culture was performed and antibiotic treatment was performed according to drug sensitivity test. The patient's other general condition was fair. Blood pressure was 132/78 and pulse 72. Physical examination was unremarkable, except for operative scars in the suprapubic and perineal areas. Bilateral ureterography revealed minimal bladder volume, cysto-rectal fistula, contrast extravasation through the rectum, and bilateral distal ureteral stricture (Figures 1,2). Cystourethroscopy revealed complete stricture of the posterior urethra with communication between the posterior wall of the bladder and the rectum. After controlling the urinary tract infection, the patient underwent bilateral ureterorectal anastomosis under laparoscopy (1-6). The ureter was implanted into the isolated rectum, which was established by mucosato-mucosa anastomosis and intramural tunnel. In this report a modified version of the Heitz-Boyer-Hoveracque technique was carried out, as the technically demanding surgical step of retrorectal pull-through of the sigmoid colon was unneccesary given that the patient already had

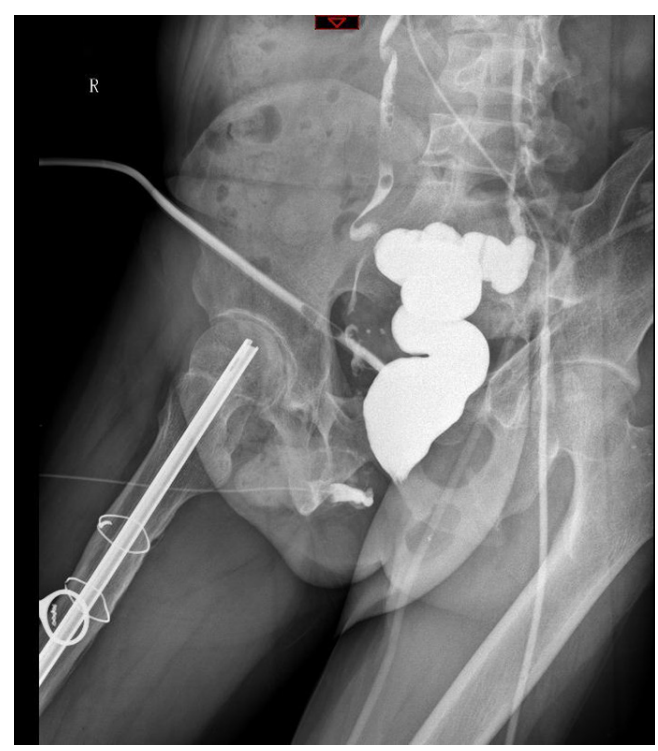

Figure 2 Image of bilateral ureterographic (contrast agent being in the rectum).

enterostomy. The recto-vesical fistula was closed. No antireflux anastomosis was performed. Postoperatively, the patient recovered well and was able to allow for complete volitional emptying. The cystostomy catheter and bilateral nephrostomy catheter were removed before discharge, and bilateral DJ stent were removed under ureteroscopy 6 weeks after operation. Six months after surgery, Doppler urinary color ultrasonography showed no hydronephrosis in both kidneys. Routine urine test indicated no urinary tract infection. No increase in blood urea nitrogen (BUN) and creatinine was observed in renal function examination.

\section{Conclusions}

About $10 \%$ of patients with pelvic fractures also have posterior urethral rupture, and about $2 \%$ of these patients have urethral-rectal fistula (7). Treatment of urethral stricture caused by pelvic fractures remains one of the most challenging problems in urology, and the related urethorectal fistula makes it more difficult to reconstruct the urethra (7-9). A distal ureteral stricture can be treated with ureterovesical reimplantation, and the 'psoas hitch' technique or a pedicled flap of bladder wall (Boari flap) could be considered for strictures greater than $5 \mathrm{~cm}$. The patient suffered from urethral stricture combined with vesicorectal fistula 27 years ago due to traffic accident, and bilateral distal ureteral stricture was found 1 year ago. The patient 
had a poor quality of life with cystostomy catheter and nephrostomy catheter. If bilateral ureteral reconstruction and urethral reconstruction are carried out directly, the patient will not only suffer a great risk of surgery, but also need a high cost. Considering the patient's condition, we decided to perform laparoscopic bilateral ureterorectal reimplantation. The surgical procedure refered to the HeitzBoyer-Hovelacque method. But there are also differences. The patient did not need to have a sigmoidal perineostomy at the same time because of a persistent enterostomy. We only cut the distal end of bilateral ureter and anastomosed it with the vacant rectum, which skillfully solved the problem of urination. It is important to emphasize that this is not a standard Heitz-Boyer-Houvelac procedure and that this type of urinary diversion should only be considered in very carefully selected cases. This surgery was performed laparoscopically and that the most relevant benefit for the patient was to avoid incontinent urinary diversion or possibly a more complex surgical procedure. In principle, anti-refluxing anastomosis can prevent urine from reflux into the kidney and cause little renal parenchymal damage. However, anti-refluxing procedures are accompanied by a higher percentage of stricture of uretero-ileal anastomosis and do not guarantee the absence of reflux (10-12). The theoretical benefit of the anti-refluxing technique has been overestimated until now despite of the frequency of stricture formation. So it is not considered. And 6 months after surgery, Doppler urinary color ultrasonography showed no hydronephrosis in both kidneys. Routine urine test indicated no urinary tract infection. No increase in blood urea nitrogen (BUN) and creatinine was observed in renal function examination. There are several advantages in this urinary diversion operation: (I) simple, less damage and less cost; (II) storing urine at low pressure, protecting kidney function, allowing for complete volitional emptying, and providing socially acceptable continence; (III) having less absorption of urinary metabolites to avoid metabolic abnormalities; (IV) no serious complications have occurred so far. The patient will be followed up to observe the long-term effects of the operation. The patient expressed satisfaction and gratitude for the success of the operation, and he believed that his quality of life had been greatly improved after the operation.

For complicated patients with total urethral stricture and enterostomy caused by car accident, this surgical method has a certain reference significance.

\section{Acknowledgments}

Funding: None.

\section{Footnote}

Reporting Checklist: The authors have completed the CARE reporting checklist. Available at https://dx.doi. org/10.21037/tau-21-298

Conflict of Interest: All authors have completed the ICMJE uniform disclosure form (available at https://dx.doi. org/10.21037/tau-21-298). The authors have no conflicts of interest to declare.

Peer Review File: Available at https://dx.doi.org/10.21037/ tau-21-298

Ethical Statement: The authors are accountable for all aspects of the work in ensuring that questions related to the accuracy or integrity of any part of the work are appropriately investigated and resolved. All procedures performed in studies involving human participants were in accordance with the ethical standards of the institutional and/or national research committee(s) and with the Helsinki Declaration (as revised in 2013). Written informed consent was obtained from the patient.

Open Access Statement: This is an Open Access article distributed in accordance with the Creative Commons Attribution-NonCommercial-NoDerivs 4.0 International License (CC BY-NC-ND 4.0), which permits the noncommercial replication and distribution of the article with the strict proviso that no changes or edits are made and the original work is properly cited (including links to both the formal publication through the relevant DOI and the license). See: https://creativecommons.org/licenses/by-nc-nd/4.0/.

\section{References}

1. Wolff HD Jr. Transvaginal ureterorectal anastomosis with partial cystectomy; case report. J Urol 1948;59:182-92.

2. Bracci U, Laurenti C. Rectal bladder in the treatment of bladder exstrophy. Eur Urol 1979;5:161-2.

3. Tacciuoli M, Laurenti C, Racheli T. Sixteen years' experience with the Heitz Boyer-Hovelacque procedure for exstrophy of the bladder. Br J Urol 1977;49:385-90. 
4. Messina M, Molinaro F, Ferrara F, et al. Continence and quality of life with the modified Heitz-Boyer-Hovelacque rectal bladder for children with urinary incontinence following bladder exstrophy. J Pediatr Urol 2016;12:174.e1-6.

5. Culp DA, Flocks RH. The diversion of urine by the HeitzBoyer procedure. J Urol 1966;95:334-43.

6. Bracci U. Urinary diversion by the Heitz-BoyerHovelacque procedure. Technique and experience. Urol Int 1968;23:63-73.

7. Guo H, Sa Y, Fu Q, et al. Experience with 32 Pelvic Fracture Urethral Defects Associated with Urethrorectal Fistulas: Transperineal Urethroplasty with Gracilis Muscle Interposition. J Urol 2017;198:141-7.

8. Xu YM, Sa YL, Fu Q, et al. Surgical treatment of 31 complex traumatic posterior urethral strictures associated with urethrorectal fistulas. Eur Urol 2010;57:514-20.

Cite this article as: Hai X, Yang J. A neo-rectal bladder by uretero-rectal anastomosis: a case report. Transl Androl Urol 2021;10(7):3080-3083. doi: 10.21037/tau-21-298
9. Gómez RG, Mundy T, Dubey D, et al. SIU/ICUD Consultation on Urethral Strictures: Pelvic fracture urethral injuries. Urology 2014;83:S48-58.

10. Pantuck AJ, Han KR, Perrotti M, et al. Ureteroenteric anastomosis in continent urinary diversion: long-term results and complications of direct versus nonrefluxing techniques. J Urol 2000;163:450-5.

11. Hohenfellner R, Black P, Leissner J, et al. Refluxing ureterointestinal anastomosis for continent cutaneous urinary diversion. J Urol 2002;168:1013-6; discussion 1016-7.

12. Hassan AA, Elgamal SA, Sabaa MA, et al. Evaluation of direct versus non-refluxing technique and functional results in orthotopic Y-ileal neobladder after 12 years of follow up. Int J Urol 2007;14:300-4. 